\title{
Following the Collapse: Regeneration or Transformation of the Urban Societies?
}

In the field of Syrian and Mesopotamian studies we must deal with many changes affecting the urban complexity and the socio-political and economic systems. In Syria, two major regional changes have been identified: one is the collapse of the Uruk system and the beginning of the second urban revolution, the other is the end of the Early Bronze Age and the beginning of the Middle Bronze Age cultures during the late third/early second millennium B.C. The terms "transition" and "collapse" are largely used in the definition of those two historical events.

Many reasons could cause the collapse of any civilization: to explain the nature of any collapse we must look at the characteristics of the period that followed it. This paper will deal with the archaeological evidence from the late third and early second millennium B.C. in northern inner Syria to illustrate, on the one hand, the reason of that collapse and, on the other hand, to show how such a collapse affected the developmental trajectories of the urban systems. 